\title{
A NOÇÃO DE SALVAÇÃO NO LIVRO V DA REPÚBLICA DE PLATÃo
}

\author{
Antonio Orlando de Oliveira Dourado Lopes \\ Universidade Federal de Minas Gerais 1
}

Resumo: A importáncia da noção platónica de salvaçæo (owrnpía) aparece quando ela é relacionada com a questão platónica por excelência da convergência entre filosofia $e$ política. A salvaçăo diz respeito ao filósofo tanto quanto ao político, $e$ isto porque os dois, para Platão, só podem ser o mesmo. Como este último pensamento é exposto de modo privilegiado no livro $V$ da República (notadamente em 473c-e), é lá também que se pode achar as reflexões mais decisivas no que concerne o tema da salvaçâo.

Palavans-chave: Filosofia-política, Platão, República, Salvação

No conjunto dos dez livros que compõem a República de Platão o livro $\mathrm{V}$ representa uma passagem. Trata-se de uma verdadeira transformação nas questōes apresentadas nos quatro primeiros livros mas que não fere a continuidade do questionamento de Sócrates e seus companheiros nem a unidade primordial da obra. Refazer o percurso desta passagem é a tarefa que, segundo acreditamos, impõe-se de saída ao intérprete do livro V.

$E$ já no início que o livro $V$ pode ser compreendido em uma tal perspectiva: após uma breve fala de Sócrates, Polemarco estende-se e puxa a manga do manto de Adimanto; este, por sua vez, interpela Sócrates e exige-Ihe que

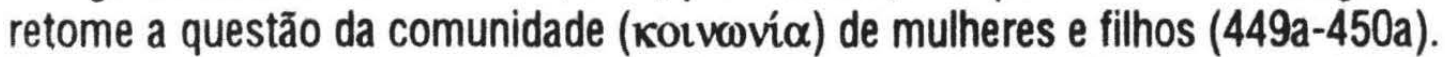

A esta altura a interrupção de Polemarco pode ser considerada em referência ao início da República quando, no livro I, o mesmo Polemarco manda um de seus escravos interpelar Sócrates que, a uma certa distância, preparava-se para retornar a Atenas (327a-b). Temos, então, em linhas gerais, uma repetição da abertura do livro I: Polemarco toma a iniciativa de convocar um outro homem a interromper Sócrates e a impedir o mesmo de "escapar" ao diálogo.

Esta repetição parece indicar-nos, em primeiro lugar, o início de um novo questionamento, início este comparável ao da própria República ${ }^{2}$. Em segundo

1. A presente exposição é a etapa inicial de elaboração da dissertaçăo de mestrado a ser apresentada ao Departamento de Filosofia do Instituto de Filosofia e Ciencias Sociais da Universidade do Rio de Janeiro, sob a orientação da Prof. Dr. Maria das Graças de Moraes Augusto.

2. Partindo desta aproximação do inicio do livro V com o livro I da Repóblica, não podemos deixar de considerar uma diferença fundamental: no livro $\mathrm{V}$ o homem que Polemarco convoca não é mais um escravo, mas Adimanto, um "companheiro" (étôipos) do diálogo dos quatro primeiros livros. Tratase de um aspecto do "novo começo" do livro V que năo poderia ser negligenciado. 
lugar, a referência ao livro I vem enfatizar a importância da interrupção como elemento integrante do diálogo e decisivo em sua composição ${ }^{3}$.

Assim, o livro $V$ nos apresenta a passagem a um novo diálogo, caracterizada não só pela interrupção de Polemarco como também pela introdução de novos temas de questionamento. Entre estes uma particular importância é atribuída à questão do início e da dificuldade inerentes ao percurso do diálogo.

Com tal riqueza de questões o livro $\mathrm{V}$ pode, então, ser considerado uma tematização da própria passagem ao novo questionamento. $A$ interrupção de Polemarco e ao novo início que ela parece sugerir corresponde o jogo com os

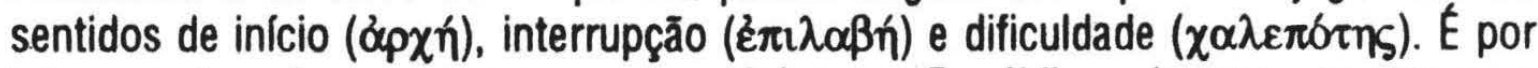
isto que tem lugar uma passagem única na República, de que encontramos testemunho nas seguintes palavras de Sócrates:

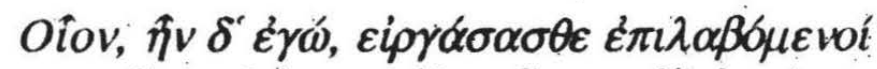

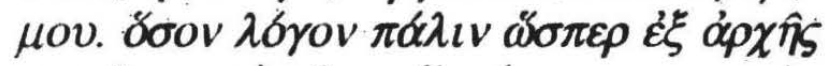

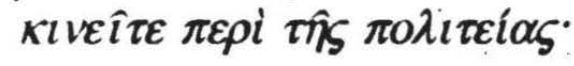

(0 que lograis fazer interrompendo-me! - dizia eu. Que pensamento sobre a constituição polftica vós botais de novo em movimento, como de início! - 450a $)^{4}$

Podemos dizer que nestas palavras de Sócrates Platão deixa manifestarse a riqueza essencial do termo ó̀pरń, sendo este extensamente empregado na tradição do pensamento grego e nela assumindo uma importância em muitos aspectos incomparável. Deste modo, ¿́pxń faz conviverem no texto de Platão os sentidos de princípio cronológico ("início", "começo"), princípio ontológico ("ser", "origem"), e governo, principalmente ${ }^{5}$. A questão do início do diálogo no livro $V$ é, desta forma, também a questão do "ser" do diálogo e também a do "poder" que a

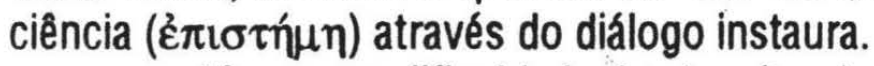

Mas se a dificuldade ( $\chi \alpha \lambda \varepsilon \pi o ́ r n s)$ deve caracterizar fundamentalmente

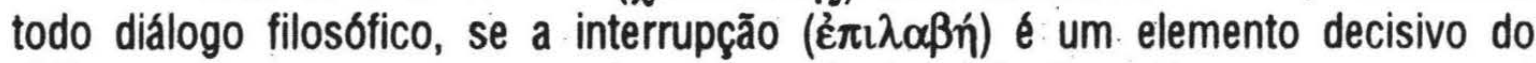
diálogo tal como nos mostra Platão na abertura do livro V, então por que é precisamente neste livro que este conjunto de questões é colocado? Por que isto não se deu antes ou depois em qualquer outro momento da Repáblica?

Cremos que a resposta a estas perguntas só nos é oferecida quando compreendemos 0 sentido que tem no livro $V$ a noção de salvaçăo ( $\sigma \omega \tau$ rnpí $\alpha)$. Um tal sentido, por sua vez, só é acessível se considerarmos o livro V da Repáblica a partir de seu questionamento central, que atinge seu ponto culminante na afirmação

3. Se desenvolvermos esta argumentação poderemos definir com maior clareza as relações entre a

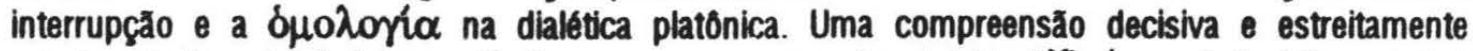

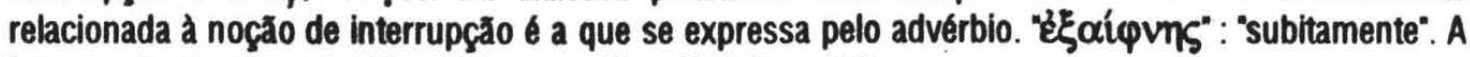
interrupção é sempre "súbita". Veja-se, no livro V: 453c e 472a.

4. A tradução é nossa. As traduções apresentadas a seguir são de nossa autoria, com exceção das ocasiōes em que se faz indicação em contrário. Sempre que possivel servimo-nos da tradução da Profa. Maria Helena da Rocha Pereira (Platão, 1987).

5. É preciso atribuir ao termo "ỏpx ń" a gravidade que the cabe no texto do diálogo platônico. Trata-se de um termo "estratégico" de Platão, empregado para indicar a convergência entre filosofia e política. 


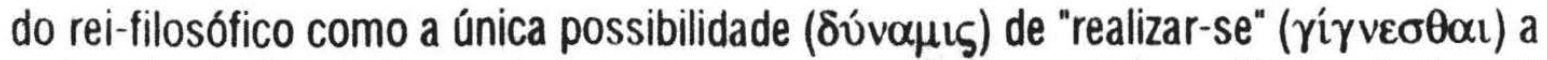
$\pi 0 \lambda ı \tau \varepsilon i \alpha(473 \mathrm{c}-\mathrm{e})$. Na verdade, pode-se mesmo dizer que todo o diálogo do livro $\mathrm{V}$ gira em torno desta célebre e controversa afirmação - controversa, aliás, já na perspectiva em que nos é apresentada no próprio texto da República (473e-474b).

Assim, a noção de salvaçăo é, de um lado, parte do questionamento que culmina na figura do rei-filósofo. De outro lado ela é ainda, como pretendemos mostrar, a compreensão que articula esta mesma formulação no quadro de toda a argumentação do livro V. É como se a elaboração da figura platônica do rei-filósofo "salvasse" 0 diálogo cheio de dificuldades do livro $V^{6}$.

Portanto, se para compreender-se a noção de salvaçăo no livro $V$ é preciso interpretar-se a figura do rei-filosofo, para compreender-se esta última também é imprescindível uma remissão à primeira. A pergunta pela possibilidade

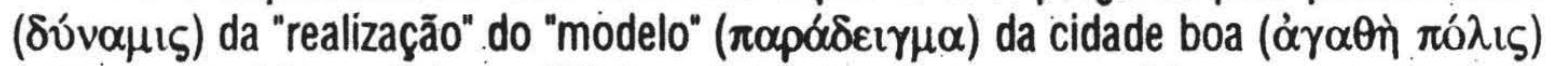

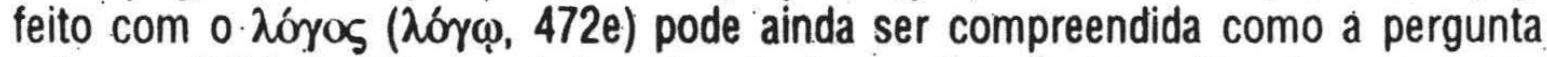

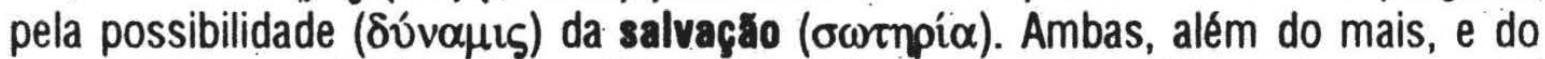

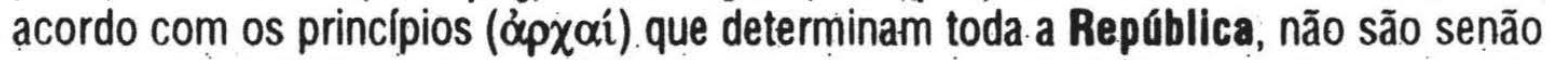

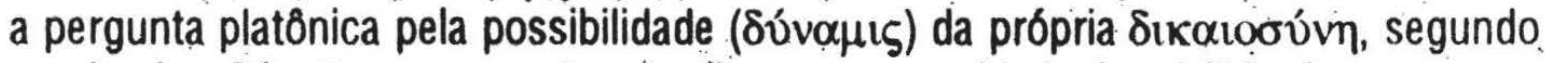
nos lembra Sócrates pouco antes de afirmar a necessidade do rei-filósofo:

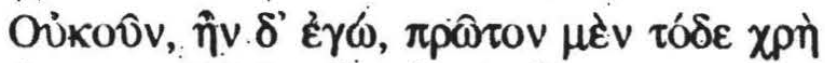

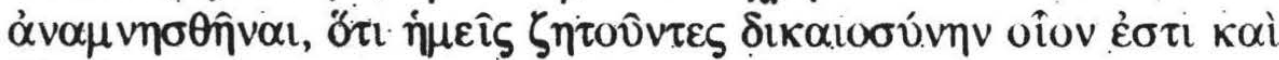

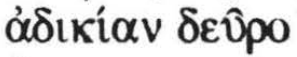

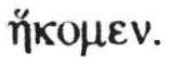

(Então, dizia eu, é preciso, primeiramente, isto ser lembrado: que nós para procurar o que é a justiça e a injustiça aqui chegamos - 472b)

No espaço do livro $V$ as três perguntas parecem equivaler-se. Vejamos, então, como se organiza a reflexão que nele se apresenta.

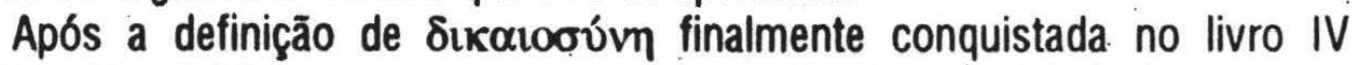

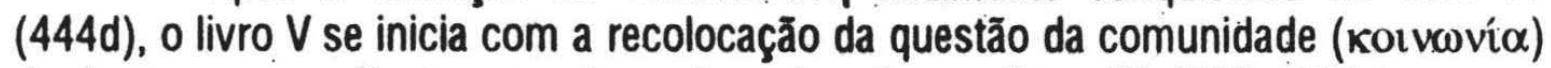
de homens e mulheres, previamente colocada no livro IV (423a-424a), e que determina a interrupção no diálogo conforme temos mostrado. Deste modo, o percurso que o diálogo nos propõe pode ser determinado nas seguintes etapas, dispostas segundo as três ondas a que Sócrates compara as dificuldades enfrentadas:

12 onda-diticuldade: homens e mulheres receberem a mesma educação

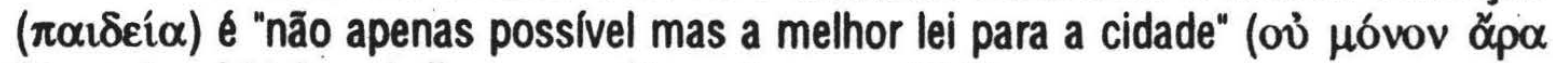

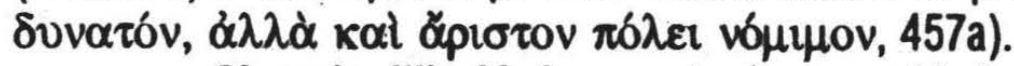

22 onda-dificuldade: quanto à comunidade (kotvoví $\alpha$ ) de mulheres e

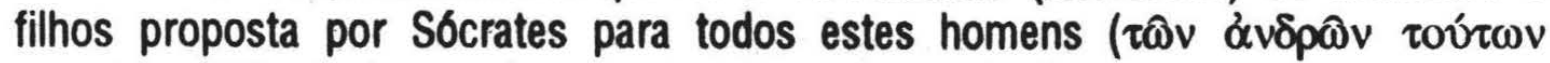

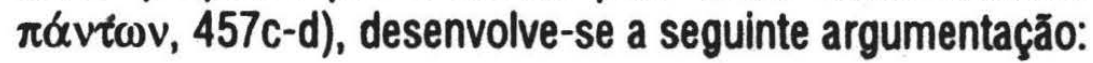

a. "o princípio do acordo ao qual se dirige o diálogo" (ó $p \chi \eta े ~ \tau \Uparrow \hat{~}$ ómotorías) é "o maior bem que temos a dizer para a disposição da

6. Segundo nossa interpretação a salvação responde pela própria estrutura interna do texto do livro $V$. 


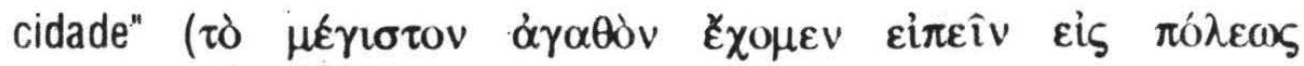
$\kappa \alpha \tau \alpha \sigma \kappa \varepsilon \cup \eta \dot{v}, 462 \mathrm{a})$;

b. não há "maior bem para a cidade do que aquilo que a reunir e a tornar

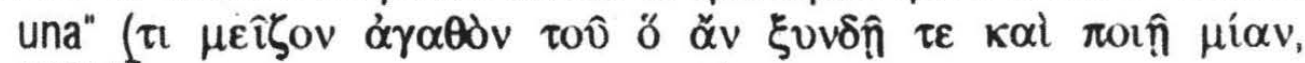
$462 b)^{7}$;

c. "a comunidade de prazer e de sofrimento une os cidadãos quando eles, no maior número possivel, se regozijam e se afligem igualmente com

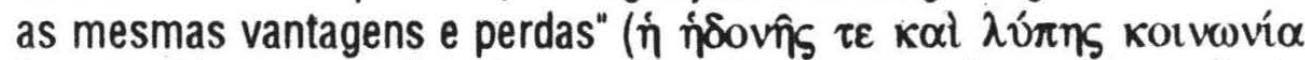

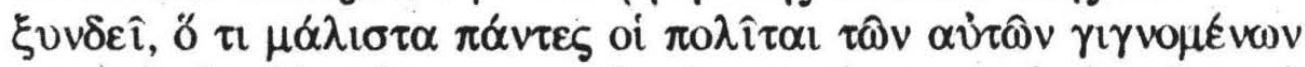

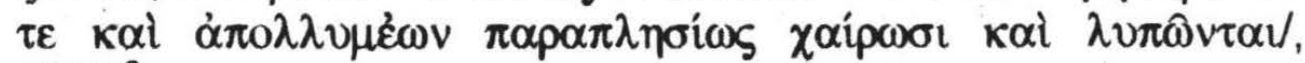
$462 b)^{8}$;

d. a causa ( $\alpha i$ íí $\alpha$ ) da comunidade de prazer e de sofrimento é "a comunidade de mulheres e de crianças, para os guardiōes" ( $\dot{\eta} \tau \hat{\omega} \mathrm{v}$

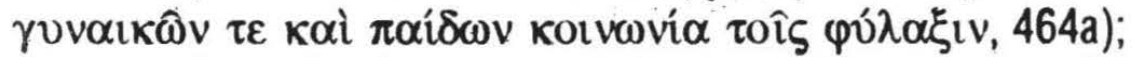

e. a causa do maior bem para a cidade (

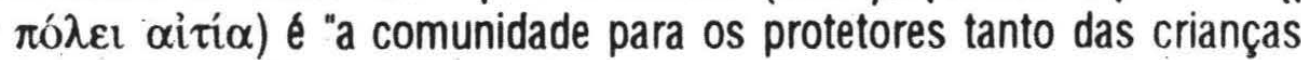

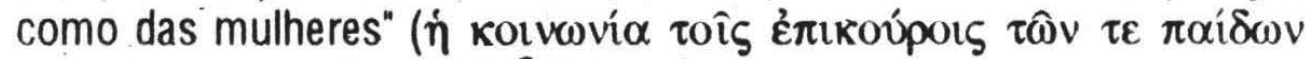

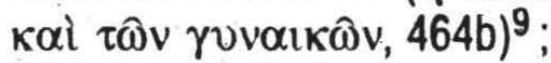

f. Sócrates arremata a argumentação dizendo que "estamos de acordo

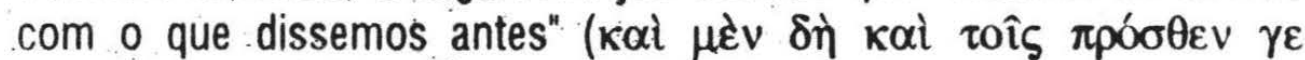
$\left.\omega \dot{\omega} \mu \lambda_{0} \gamma_{0} \hat{0} \mu \varepsilon v, 464 b\right)^{10}$, em nítida referência ao que dissera no início (462a, item "a" relativo à $\mathbf{2}^{2}$ onda-dificuldade);

3! onda-dificuldade: não há "termo dos males(...) para as cidades"

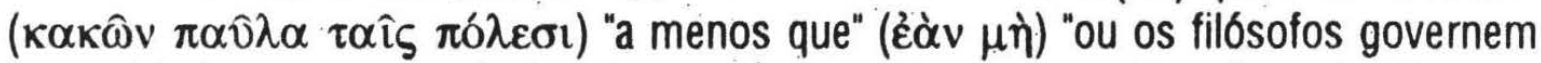
nas cidades ou os declarados reis e governantes filosofem legítima $e$

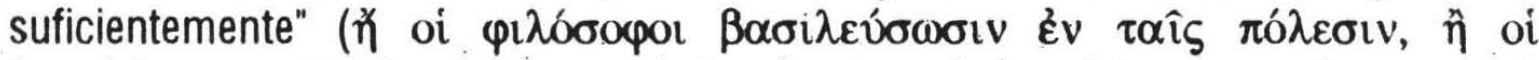

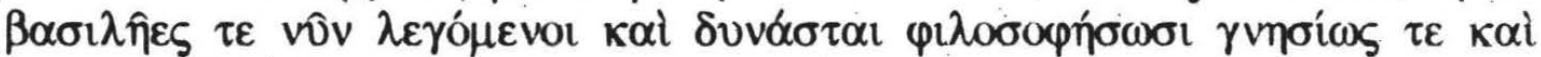
iк $\alpha$ vas, 473c-e).

$\mathrm{Na}$ parte final do livro $\mathrm{V}$, que sucede à figura do rei-filósofo (3? onda-

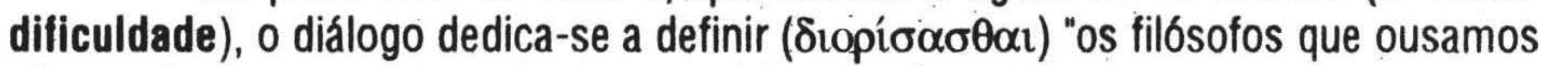

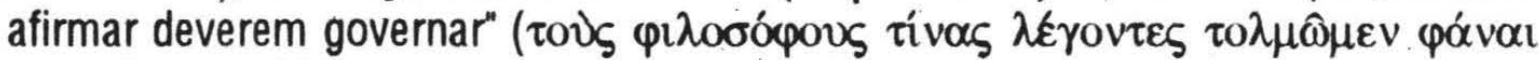

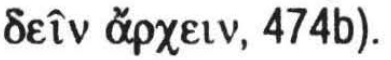

\section{Platão, 1987, p. 231.}

8. Platão, 1987, p. 232.

9. Traduzimos o termo técnico da Repáblica "Ėđí koupos" por "protetor". Levamos em consideração três aspectos distintos:

a. a importância deste termo no livro $\mathrm{V}$ da Repáblica e nos demais livros em geral;

b. os sentidos nele encontrados tanto de "socorro", "ajuda" e "auxlio" como de "salvaguarda" e "proteção";

c. a necessidade de manter-se a univocidade na tradução ao longo de todo o texto. Deste modo, no trecho 463b, que citaremos mais à frente, e em que encontramos o mesmo termo, optamos pela mesma tradução. A tradução de "غ̇лí Koupos" por "protetores" é da Profa. Maria Helena da Rocha Pereira, na tradução do passo 464d (Platão, 1987, p. 236).

10. Platão, 1987, p. 236. 
Podemos, então, estabelecer a figura do rei-filósofo como uma espécie de divisor de águas do livro V, onde, na primeira parte (449a-473c), encontramos a colocação das questões a que a figura do rei-filósofo pretende apresentar algum tipo de resposta (ou seja, as três ondas-dificuldades); na segunda parte (473e-480a), por outro lado, temos uma explicitação da mesma figura do rei-filósofo, considerada a partir da variedade de significações que a tradição atribui ao termo "filossofo" em geral. É preciso determinar-se com toda a precisão possivel, a "qual" filósofo se está referindo.

Desta forma, vemos que a figura do rei-filósofo não pretende responder de algum modo apenas à questão imediatamente a ela ligada, a saber, a $3^{2}$ onda-

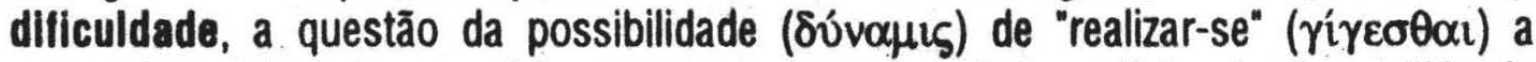
$\pi 0 \lambda \iota \tau \varepsilon i \alpha$ elaborada por Sócrates e seus companheiros $(\lambda \hat{\gamma} \gamma \omega)$. 0 rei-filosofo configura, outrossim, 0 encaminhamento das respostas também à $1^{\mathbf{l}}$ e à $2^{\mathfrak{z}}$ ondasdificuldades, uma vez que só há sentido em encaminhar-se e resolver-se as

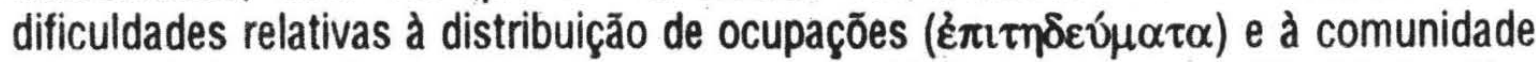
( $\kappa o t v \omega v i ́ \alpha$ ) entre homens e mulheres caso a cidade em que tais dificuldades têm lugar possa "realizar-se" ( $\gamma^{\prime} \gamma_{\gamma} v \sigma \theta \alpha$ ). É por isto que as ondas-dificuldades de que nos fala Sócrates são maiores e mais terriveis à medida em que se sucedem, pois cada nova onda-dificuldade "acumula" as que the antecederam.

De acordo com nossa interpretação, as três dificuldades que enfrentam Socrates e os demais participantes do diálogo podem não passar de desdobramentos de uma única dificuldade ( $\chi \alpha \lambda \varepsilon \pi o ́ r m s)$, a saber, a dificuldade da

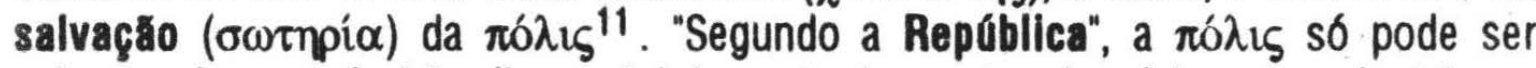
salva se for possivel "realizar-se" ( $\gamma^{\prime} \gamma v \varepsilon \sigma \theta \alpha l$ ) a $\pi 0 \lambda \iota \tau \varepsilon i ́ \alpha$ elaborada pelo $\lambda o ́ \gamma o s$. Por "realizar-se" compreende-se a "realização" de algo que for muito semelhante $\left(\tau_{1}\right.$ ópotó $\alpha \tau \tau$ - veja-se 472b-473b) à boa cidade.

E por isso que nós lemos no mesmo livro $V$ que o "povo" ( $\left.\delta \hat{\eta} \mu \circ \varsigma_{)}\right)$da

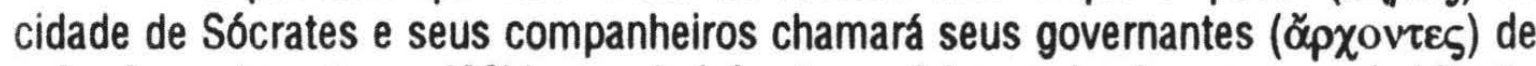

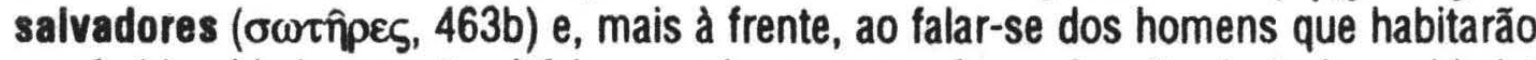
a referida cidade, que "a vitória que eles vencem é a salvaçăo de toda a cidade"

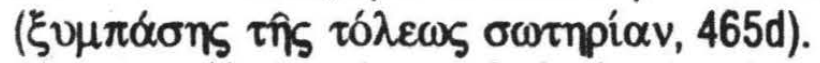

Nestas duas referências à salvação não encontramos nenhuma espécie de desenvolvimento ou explicitação desta noção, ou qualquer comentário que as esclarecesse, assim como não os há nas três únicas outras ocasiōes no livro $\mathrm{V}$ em

11. É apenas no livro VI que encontramos explicitada a compreensão da dificuldade de salvação

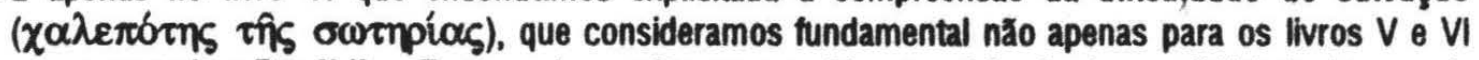
mas para toda a Repablica. Trata-se da ocasiáo em que Sócrates, falando da possibilidade de um reifilósofo e supondo um regime de transmissão hereditária de poder, refere-se aos "filhos, nascidos

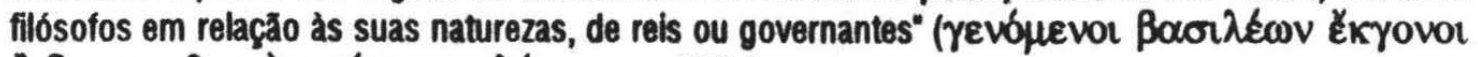

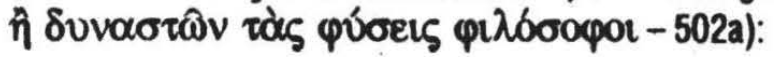

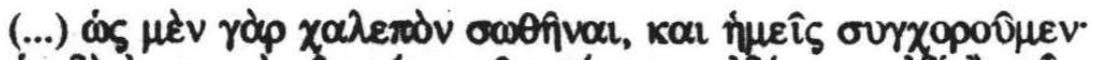

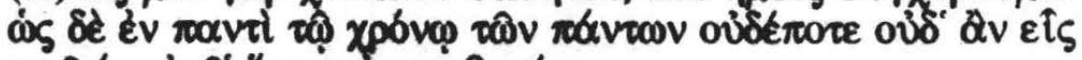

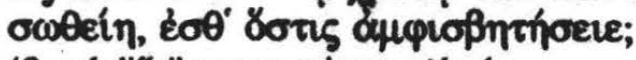

(Que é difícil que se salvem, até nós concordamos. Mas que em todos os tempos nem um só se salvasse jamais entre todos, há quem o discuta ? 502a-b. Platăo, 1987, p. 299) 
que se refere à salvaçăo: $453 c, 455 b, 467 e$. Sendo assim, em que consiste propriamente uma interpretação que pretende colocar a noção de salvação lado a lado com a figura do rei-filosofo e fazer de ambas o centro em torno do qual gira todo o questionamento do livro V? Como se sustenta esta interpretação em vista de tão poucas referências as quais, ainda por cima, parecem ser excessivamente econo̊micas para tão importante papel?

Se observamos com mais atenção vemos que, quando Gláucon,

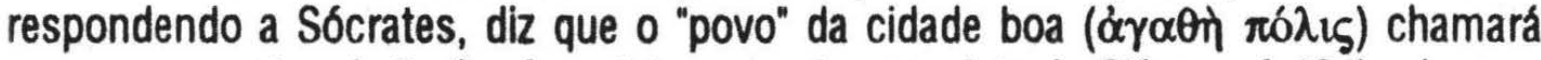
seus governantes de "salvadores" (a resposta completa de Gláucon é: "Salvadores e

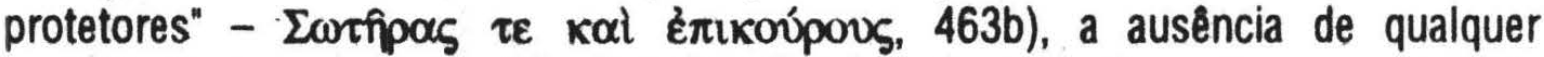
explicitação acerca do sentido de salvaçẫo al em jogo ou de qualquer comentário sobre a resposta de Gláucon não parece indicar falta de importância da noção de salvação no texto do livro V. Do mesmo modo, a comparação de Sócrates dos cidadãos da cidade boa a atletas vencedores que conquistam "a salvação de toda a cidade" parece-nos remeter a uma compreensão subjacente a todo o diálogo e que só por isto pode dispensar explicaçōes sobressalentes.

Em ambos os casos o diálogo sugere, por seus contextos específicos, que à noção de salvaçăo convem uma medida própria, um certo comedimento no qual não há lugar para outra apresentação que não seja "econômica". Não se poderia estabelecer um diálogo que se detivesse na tematização da salvação. Ao que parece, este modo próprio da noção platônica de salvaçăo apresentar-se, econômico, conciso, corresponde ao seu sentido fundamental.

Em um terceiro momento do livro $\mathrm{V}$, em que Platão refere-se à noção de salvação, encontramos uma compreensão que acrescenta novos argumentos à nossa interpretação. Trata-se, a bem dizer, da primeira vez em que se fala de salvação no livro $V$ da República, além de ser a ocasião em que melhor se oferece a oportunidade de atingir seu sentido seu sentido mais próprio.

Estamos evocando um momento do diálogo inicial do livro $\mathrm{V}$, quando Sócrates e seus companheiros encontram-se às voltas com a $1^{\mathbf{2}}$ onda-dificuldade, segundo as próprias palavras de Sócrates que lemos adiante (457b-c). A esta altura o diálogo é marcado pelo novo início que a recolocação da questão da distribuição

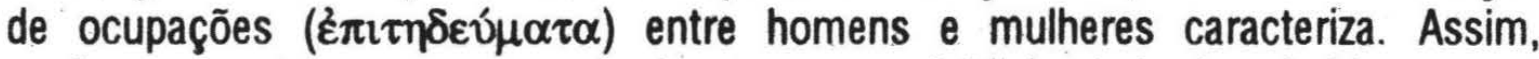
conforme mostramos no começo de nossa exposição, ao lado da referida questão vemos um não menos importante questionamento acerca da possibilidade do

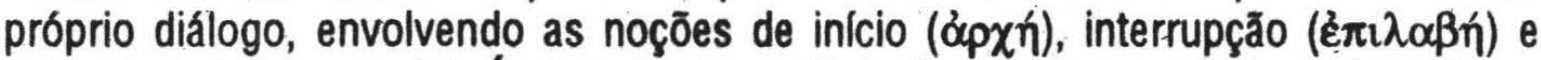
dificuldade ( $\left.\left.\chi \alpha \lambda \varepsilon \pi \sigma^{\prime} \tau\right\rceil\right)$ ). É partindo da confluência destas questões que Sócrates e Gláucon desenvolvem o seguinte diálogo:

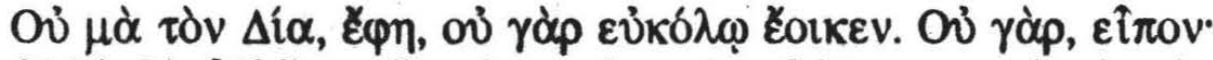

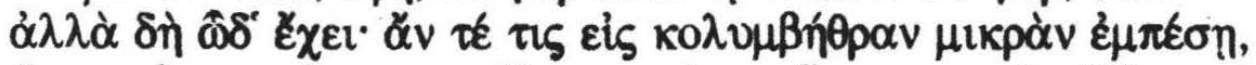

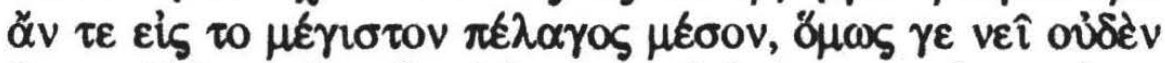

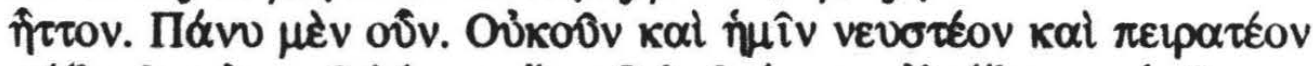

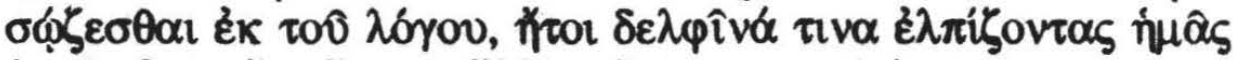

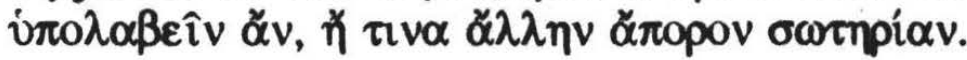

(Gláucon: Por Zeus que não parece cómodo!

Socrates: Não, com efeito, dizia eu. Mas, assim sendo, se alguém cai 
em uma pequena piscina ou no meio do enorme mar

semelhantemente não nada menos.

Gláucon: De modo algum.

Sócrates: Entăo também nós temos que nadar e tentar ser salvos a

partir do גoros, ou esperando que algum golfinho nos carregue ou

alguma outra inacessivel salvação. 453-e $)^{12}$

Neste pequeno trecho vemos a comparação da situação em que se encontra o diálogo a um homem lançado ao mar. Chamemos a situação do homem no mar, enunciada por Sócrates, de "imagem", mesmo sabendo tratar-se de um título precário e sem nos preocuparmos, por ora, em precisar como se relaciona

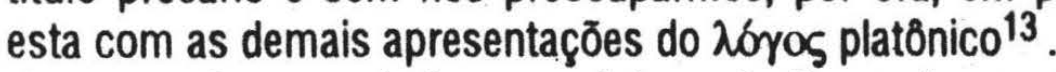

Ora, seguindo nossa interpretação, podemos dizer que a dificuldade do diálogo que a "imagem" elaborada por Sócrates pretende traduzir tanto diz respeito à

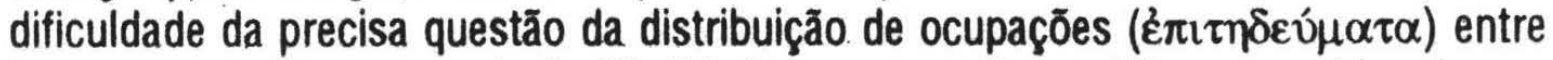
homens e mulheres quanto à dificuldade concernente ao diálogo considerado em sua própria natureza. Deste modo, apesar de referir-se diretamente apenas à primeira da série de três ondas-dificuldades do livro V, a "imagem" elaborada por Sócrates pode ser compreendida em relação a todo o questionamento que, como vimos, atinge seu cume na figura do rei-filósofo.

Por um lado, já mostramos que cada onda-dificuldade "acumula" a anterior, estando as três indissociavelmente ligadas entre si. Remetendo-se à 1" onda-dificuldade, a "imagem" elaborada por Socrates refere-se também, necessariamente, às outras duas. Por outro lado, a possibilidade da cidade boa, que depende do rei-filossofo para "realizar-se", está necessariamente relacionada também à possibilidade do diálogo. Se levamos a sério a configuração do diálogo platônico, que diálogo seria possivel fora dos limites (öpor) da $\pi \hat{\alpha} \lambda_{1 s}$ ? Ou, de modo ainda mais claro: que sentido há em pensar em diálogo fora dos limites da $\pi 0 ́ \lambda ı \varsigma$ ?

Relacionando, deste modo, a "imagem" elaborada por Sócrates a todo 0 questionamento do livro $V$, e não apenas à 11 onda-dificuldade, acreditamos poder aproximar a "imagem" à figura do rei-filosofo (473c-e). Como mostramos acima, também esta última não se limita a encaminhar uma resposta apenas à $3^{2}$ ondadificuldade. Na verdade, ambos os momentos parecem corresponder-se, cada qual apresentando de um modo o núcleo do diálogo do livro V: a "imagem" do homem lançado ao mar no início do questionamento a figura do rei-filosofo em seu cume.

Retomamos, portanto, nossa argumentação anterior, quando diziamos

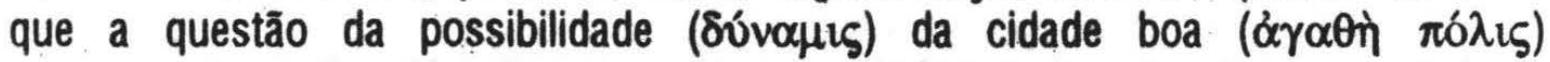

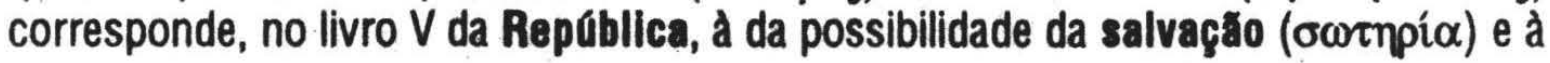

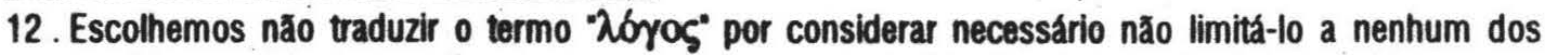
sentidos parciais de que dispomos comumente para traduzt-10. A compreensão do que seja o sentido platonico de " $\lambda 6 \gamma_{05}$ " 6, antes, a "meta" de nossa exposição, que não poderia deixar-se limitar por um ponto de partida parctal.

13. Abrimos mão, no momento, de um confronto tanto com os "mitos" encontrados em diversos diálogos de Platáo como com a conhecida "estória" da libertaçăo da caverna, que aparece no livro VII da Repáblica. Ambas as comparações nos parecem necessárias para uma efetiva compreensão do sentido disto que provisoriamente chamamos de "imagem" elaborada por Sócrates. 


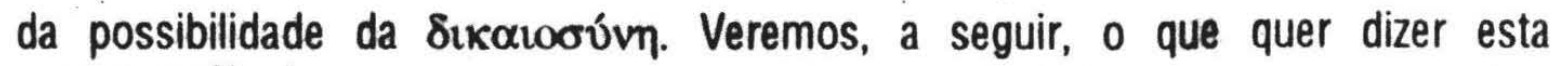
correspondência.

Temos construido nossa argumentação em torno a três das cinco referências à noção de salvação encontradas no livro $V^{14}$. Duas delas, as que abordamos em primeiro lugar, mostram a salvação como salvaģẫo da $\pi$ ó $\lambda \iota s$ : na

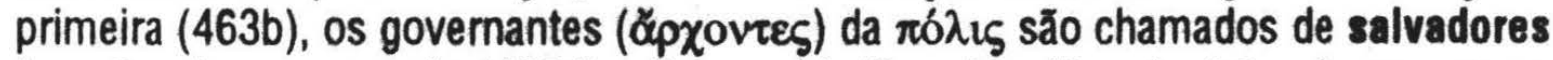

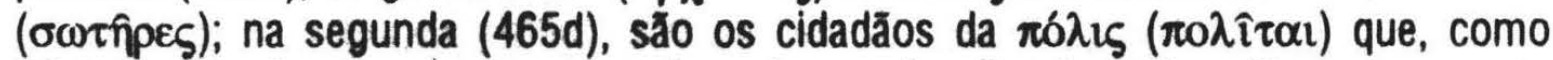

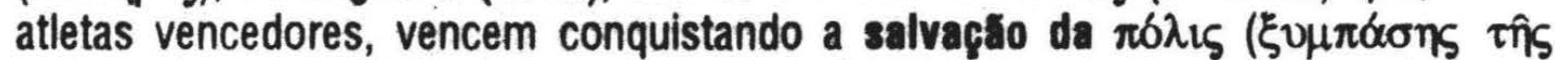

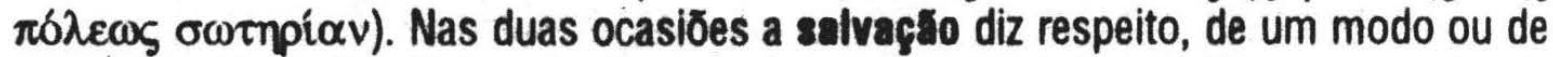

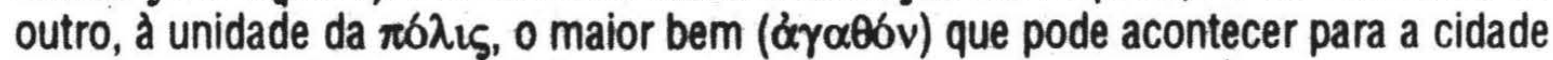
$(\pi \delta \hat{\lambda} \varepsilon \mathrm{l})$, como vimos anteriormente (462a-b).

Entretanto, na terceira referência à salvaģão que abordamos (453d-e), esta nã̀o aparece com o mesmo sentido determinado de salvaģæào da $\pi$ ó $\lambda$ ıç. Lá, segundo a "imagem" elaborada por Sócrates, "nós" é que podemos ser ou não ser salvos. $E$ "nós", no diálogo de Platão, parece dizer: "nós, o diálogo".

Assim, a "imagem" do homem lançado ao mar acena para os perigos do diálogo, mas também para suas potencialidades. Mas que perigos e potencialidades são estes?

Sem dúvida a resposta a esta questão não é fácil nem imediata. Estamos vendo, todavia, que Platão constró o texto da Repáblica movido pela mútua

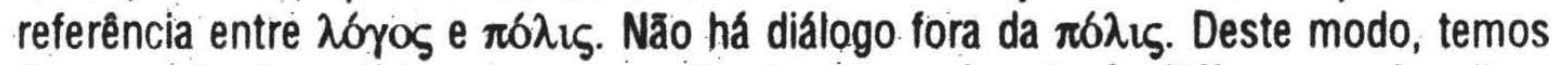
já um ponto de partida na compreensão de que a salvação do diálogo, a salvação a partir do $\lambda$ ó ${ }^{\circ}$ de que nos fala Socrates (453d), se não é a mesma que a salvaçăo da $\pi$ ó $\iota_{1 \zeta}$, está, ao menos, a ela estreitamente vinculada.

Para que se esclareça este vínculo é preciso determinar-se o que propriamente vem a ser uma e outra salvaģão. Ora, esta determinação só é possível, por sua vez, quando consideramos um terceiro sentido de salvaçăo, o de salvação da alma ( $\psi \cup \chi \eta ்)$. É no Fédon que encontramos tematizada esta salvaçăo, em uma compreensão diretamente ligada à argumentação de Sócrates sobre a imortalidade da alma. Em uma fala de Sócrates, então, nós lemos:

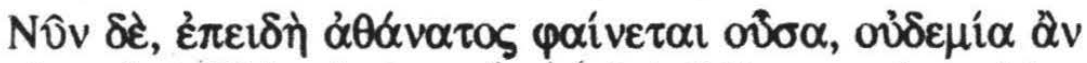

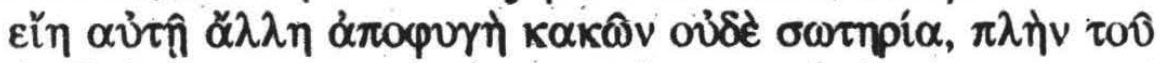

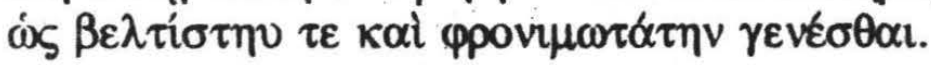

(Mas agora, uma vez que a alma aparece sendo imortal, não haveria para ela nenhuma outra fuga dos males nem, tampouco, nenhuma salvação que não tornar-se muitissimo boa e sábia. Fédon 107c-d)

Aqui a salvação é "tornar-se muitíssimo boa e sábia", o que só é possível

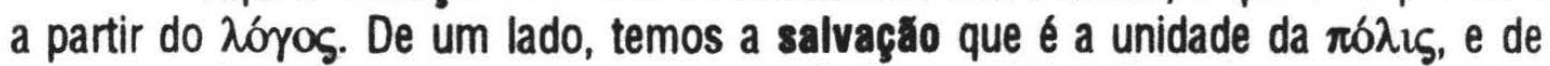
outro, a salvação que torna a alma ( $\left.\psi v \chi x^{\prime}\right)$ "boa e sábia". Tanto uma como outra

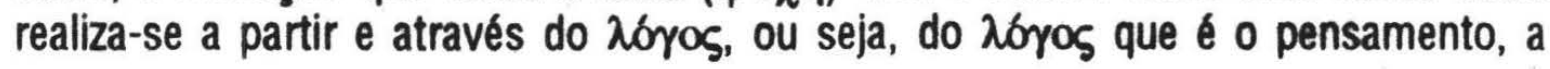

14. As duas outras referências à salvação encontradas no livro V da Ropáblica (455b; $467 e$ ) não serão abordadas no espaço reservado às reflexōes que por ora apresentamos. Ambas fazem parte de um estudo subseqũente a este, que ainda aguarda por ser realizado. 


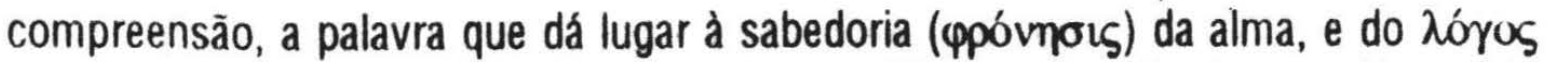
que é a palavra da ágora ateniense, a palavra política por excelência, que dá sentido tanto à vida privada quanto à pública. A mútua referência entre $\pi \delta ́ \lambda 1 s$ e $\lambda o ́ \gamma o \varsigma$

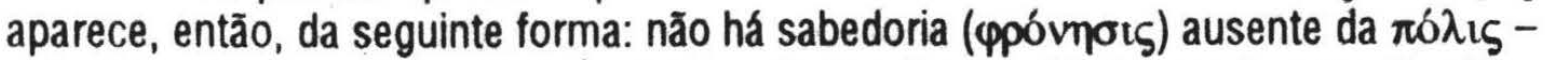
não há unidade política alheia ao $\lambda$ óyos. Salvaçăo da cidade e salvaçăo da alma equivalem-se.

Podemos, portanto, dizer que, em sentido fundamental, tanto a salvaçăo da cidade como a salvaçăo da alma são sempre e necessariamente salvaçăo a

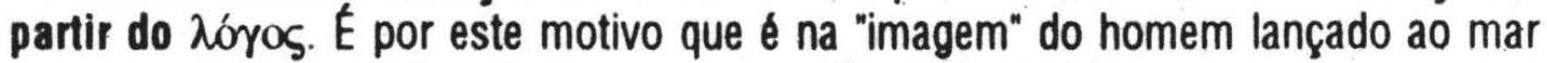
que encontramos a salvação em sua perspectiva mais decisiva.

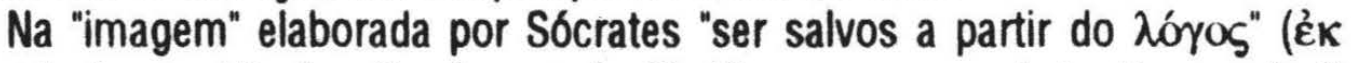

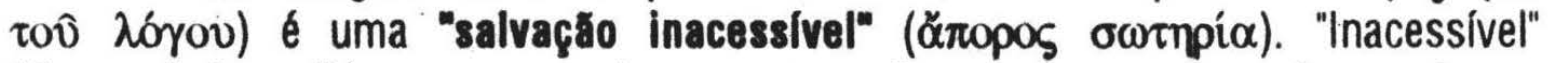
(ă opos) é aquilo que nunca chega, o que não acontece nem pode acontecer. Portanto estabelecer-se, nesta fala de Sócrates, uma evidente tensão entre a "nossa"

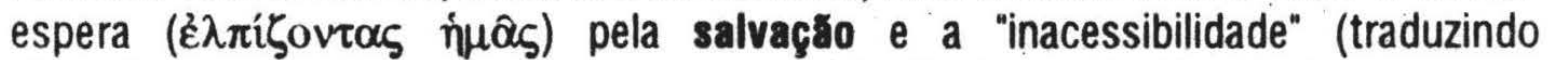

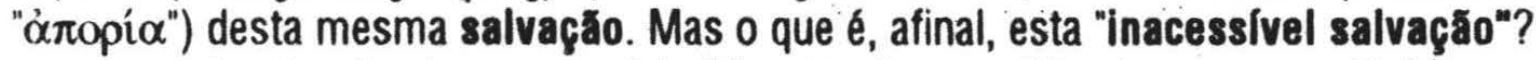

A salvação de que nos fala Sócrates é exemplificada por um golfinho que,

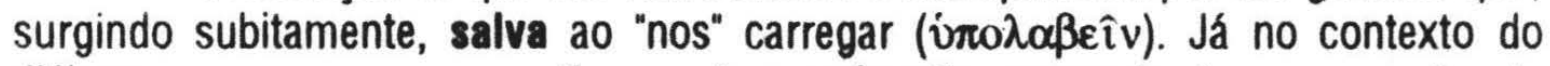
diálogo em que aparece a "imagem", a salvaçăo esperada é a superação da dificuldade acerca da distribuição de ocupações entre homens e mulheres. Em um terceiro ponto de vista, tomando em consideração todo o questionamento do livro $\mathrm{V}$, a salvação é o que torna possivel a cidade boa ( $\alpha \gamma \alpha \theta \dagger i n$ $\pi \dot{0} \lambda$ is). 0 que têm em comum estes três níveis do diálogo?

De certa forma a resposta a esta pergunta já está dada. Não dissemos antes que as três ondas-dificuldades que estruturam o diálogo do livro $V$ podem ser consideradas desdobramentos da dificuldade de salvaçăo? Pois o que há em comum entre as três perspectivas da salvaçăo que se encontram na "imagem" do homem lançado ao mar, ou melhor, o que une estas três perspectivas, é justamente

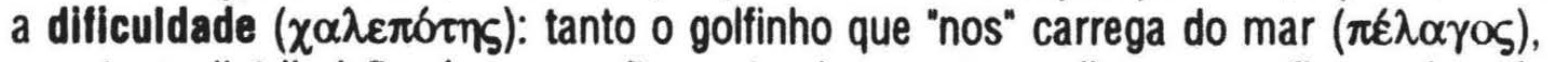
quanto a distribuição de ocupações entre homens e mulheres e a figura do reifilosofo são salvaçōes possiveis ( $\delta v v \alpha \tau \alpha i)$ ), porém dificeis ( $\chi \alpha \lambda \varepsilon \pi \alpha i$ ).

Preparando seus ouvintes para a figura do rei-filosofo, Socrates Ihes fala, referindo-se antecipadamente a esta, de uma alteração ( $\mu \varepsilon \tau \alpha \beta 0 \lambda \eta ́)$ na cidade que

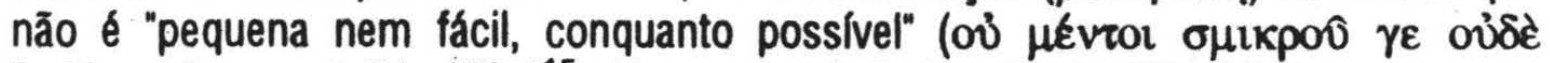

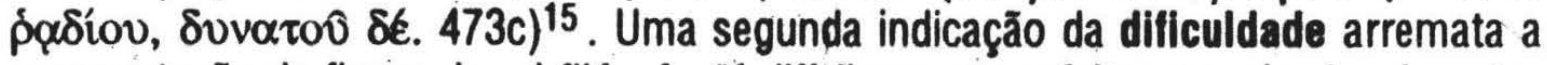
apresentação da figura do rei-filossofo: "é difićil ver, com efeito, que alguém de outro modo não poderia ser feliz, nem em relação à vida privada nem à pública" ( $\chi \alpha \lambda \varepsilon \pi \grave{v}$

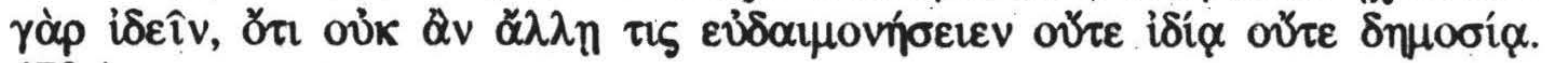
473e)

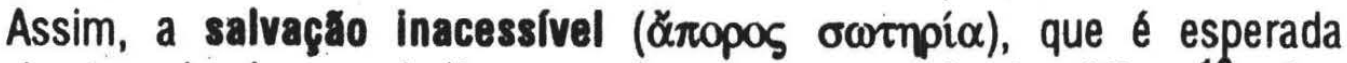

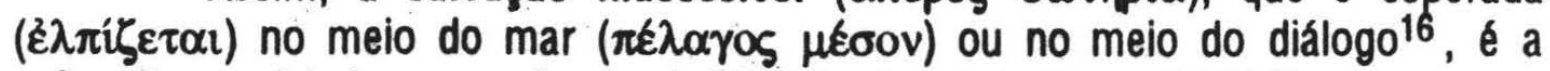

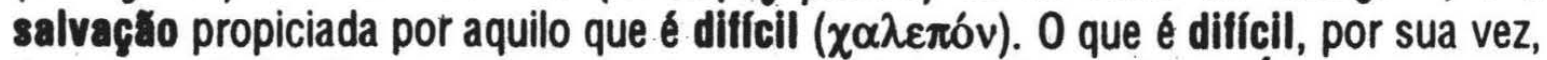
é o que pode "realizar-se" ( $\gamma^{\prime}$ iveoo $\theta$ r), mas que nunca "se realizou". É o caso do rei-

15. Platão, 1987, p. 251.

16. Composta por 10 livros, a Repóblica de Platão tem seu meio aritmético entre os livros V e VI. 
filósofo. É por nunca se ter "realizado" que se questiona se o rei-filósofo é ou não possivel - isto é, que faz sentido colocar-se esta questão.

Entretanto, se atribuirmos ao dizer ( $\lambda \varepsilon \hat{\varepsilon} \varepsilon \imath \mathrm{v}$ ) do diálogo platônico toda a

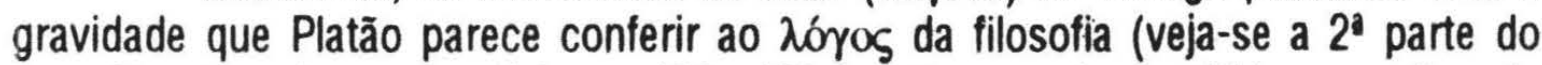
livro $V$, segundo nossa divisão: $473 \mathrm{e}-480 \mathrm{a}$ ), não nos é permitido suspeitar da

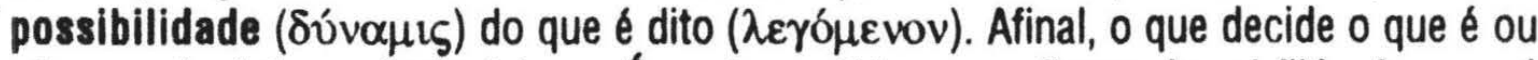
não possível é o próprio $\lambda o ́$ yos. É neste sentido que a figura do rei-filósofo, que é "apenas dita", ainda que nunca se tenha "realizado", é dificil.

Como diźamos no início, o livro $V$ da Repáblica representa uma passagem. Áquela altura caracterizávamos esta passagem segundo a retomada do antigo questionamento sobre a distribuição de ocupaçōes entre homens e mulheres.

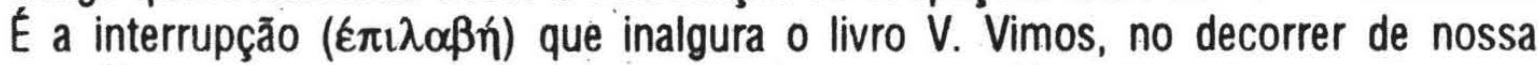
exposição, que a passagem que verdadeiramente se dá no livro $V$ é, antes, a que

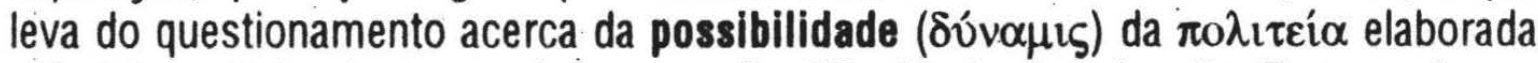
pelo $\lambda$ ó ${ }^{\circ}(\lambda o ́ \gamma \omega)$ ao questionamento da dificuldade de salvação. Trata-se de um questionamento que se revela tanto mais determinante quanto se leva em consideração que a passagem de um a outro questionamento acarreta não apenas a transformação da questão mas também a do próprio modo de questionar.

Se, por um lado, dizemos que a dificuldade de salvaçăo aparece como fundo do questionamento de toda a República, por outro ela permanece latente às discussões abordadas e visível apenas à luz de uma interpretação que considere devidamente a figura do rei-filósofo. A noção platônica de salvação cabe, como dizfamos, uma medida própria.

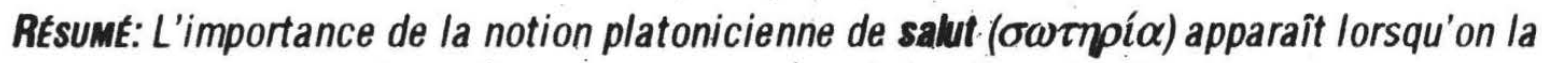
met en rapport avec la question platonicienne par excellence de la convergence entre la philosophie et la politique. Le salut concerne le philosophe aussi bien que le politique, et cela parce que tous les deux, pour Platon, ne peuvent être que le même. Comme une telle pensée est exposée de façon privilégiée au livre $V$ de la République (notamment à $473 c-e)$ c'est là aussi qu'on trouvera les réfléxions les plus décisives en ce qui appartient au thème du salut.

\section{Bibliografia}

PLATÃo. The Republic of Plato. Edição do texto grego por James Adam. Cambridge: Cambridge University Press, 1969, $2 v$.

PLATÃo. Res publica. Edição do texto grego por John Burnet. Oxford: Oxonii e Typographeo Clarendoniano, 1965.

PLATÃo. A República. Tradução por Maria Helena da Rocha Pereira a partir da edição do texto grego de John Burnet. Lisboa: Fundação Calouste Gulbenkian, $1987,5^{\mathfrak{a}}$ edição.

PLATÃo. Phédon. Tradução e edição do texto grego por Léon Robin. Paris: Les Belles Lettres, 1957. 